\title{
Emotional Gratification in Entertainment Experience. Why Viewers of Movies and TV Series Find it Rewarding to Experience Emotions
}

\author{
Anne Bartsch \\ University of Augsburg
}

Bartsch, A. (2012). Emotional gratification in entertainment experience: Why viewers of movies and television series find it rewarding to experience emotions. Media Psychology, 15(3), 267-302. doi:10.1080/15213269.2012.693811

The definitive version is available at http://www.tandfonline.com/doi/abs/10.1080/15213269.2012.693811

This article may not exactly replicate the final version published in the previously mentioned Journal. It is not the version of record and is therefore not suitable for citation.

Acknowledgements: The author wishes to thank Reinhold Viehoff, Roland Mangold, and Peter Vorderer for their generous support and advice concerning the present research. She also extends her appreciation to the German Research Foundation for providing financial support.

Funding: This work was supported by the German Research Foundation [grant number Vi 95/17].

Corresponding author: anne.bartsch@phil.uni-augsburg.de 


\begin{abstract}
This paper presents four studies designed to assess different types of gratifications that can be associated with the experience of emotions in movie and TV audiences. Exploratory and confirmatory factor analyses of a pool of statements derived from qualitative interviews revealed three factors that reflect rewarding feelings: 1) fun, 2) thrill, and 3) empathic sadness, and four factors that reflect the role of emotional media experiences within the broader context of individuals' social and cognitive needs: 4) contemplative emotional experiences, 5) emotional engagement with characters, 6) social sharing of emotions, and 7) vicarious release of emotions. Validation analyses showed that the scales developed to assess these factors are predicted by the experience of emotions and meta-emotions and served in turn to predict different aspects of positive content evaluation. Results are discussed with regard to theoretical issues including entertainment audiences' voluntary exposure to unpleasant feelings, and the role of entertainment in psychosocial need satisfaction and eudaimonic well-being.
\end{abstract}

Keywords: entertainment, emotion, gratification, need satisfaction, well-being 
Emotional Gratification in Entertainment Experience. Why Viewers of Movies and TV Series Find it Rewarding to Experience Emotions

Emotions are often assumed to be the heart of media entertainment, be it in the form of movies, novels, TV programs, music videos, or computer games. Entertainment audiences want to have a good laugh, they want to be kept at the edge of their seats, or be moved to tears. Ample evidence has accumulated in the field of media psychology that not only supports the pivotal role of affect in media entertainment, but that also provides theoretical explanations why affective experiences can be desirable and rewarding for media users. This paper reviews the research literature on affective factors in entertainment experience and presents a series of four studies designed to provide evidence of and measurement for different types of emotional gratification in individuals' experience of movies and TV series.

Special attention is given to the distinction between different theoretical roles of emotion in entertainment experience: On the one hand, the experience of moods and emotions per se can be gratifying, including for instance individuals' sense of pleasure, excitement, or sentimentality during media exposure (cf., Oliver, 1993; Zillmann, 1988; Zuckerman, 1979). On the other hand, it has been proposed that emotional media experiences can also be gratifying in an indirect manner in that they contribute to the gratification of individuals' social and cognitive needs (cf., Cupchik, 1994; Oliver \& Bartsch, 2010). The aim of the present research is to provide a systematic assessment of both direct and indirect forms of emotional gratifications in movie and TV audiences.

Following a methodological tradition of uses and gratification research, a qualitative interview study was conducted, followed by a series of questionnaire studies to detect latent dimensions in individuals' agreement with a pool of statements derived from the interviews. However, unlike most uses and gratification research, the interviews and questionnaire items were centered around a specific theoretical element, that is, the gratification potential of emotions. Rather than asking respondents about their reasons for using a given medium or 
program type in general, the participants of the present research were asked about their feelings and emotions when watching movies or TV series, whether they liked to experience these feelings, and if so, why. This focus on a limited and theoretically saturated domain of the media gratification landscape makes it possible to build on existing experimental and survey research about affective factors in individuals' media preferences. This makes it easier, on the one hand, to interpret the self-report data, and on the other hand to use these data to identify areas that could benefit from more in-depth theoretical scrutiny and experimental research.

\section{Theoretical Background}

For a large part, entertainment research has focused on the first group of emotional gratification factors mentioned above, that is, on the role of moods and emotions as rewarding feelings that can be sought by media users as an end in themselves - including feelings of fun, thrill, or sentimentality for example (cf., Oliver, 1993; Zillmann, 1988; Zuckerman, 1979). However, a growing number of "non-hedonistic" approaches have also been developed to account for the appeal of media experiences that are not readily explained in terms of pleasant, exciting or otherwise desirable feelings (cf., Cupchik, 1994; Oliver \& Bartsch, 2010; Tamborini, Bowman, Eden, Grizzard, \& Organ, 2010; Vorderer \& Ritterfeld, 2009). Relevant to the present topic, non-hedonistic forms of entertainment gratification are often assumed to involve emotions as well, though on a different theoretical level. For example, the experience of emotions, including painful and unpleasant feelings, may be functional in stimulating other rewarding experiences such as parasocial relationships (Rubin \& Perse, 1987), or selfreflection and insight (Cupchik, 1994; Oliver \& Bartsch, 2010). In this case, the experience of emotions is not considered as an end in itself but rather as a stimulus or catalyst that can foster other types of gratification processes. The following section gives an overview of core assumptions and research findings concerning both approaches.

\section{Entertainment Gratifications Associated With the Experience of Emotions Per Se}

Mood management. The idea that gratification can be derived from the experience of 
moods and emotions per se is perhaps most evident in mood management theory (Zillmann, 1988). Mood management theory assumes that individuals prefer an intermediate level of arousal that is experienced as pleasant. In addition to balanced arousal, mood management theory highlights the gratification of positive affective valence, and the gratification associated with the absorption potential of strong emotions that can help distract individuals from negative thoughts (for an overview, see Knobloch-Westerwick, 2006).

Affective disposition. Affective disposition theory (Zillmann \& Cantor, 1977) draws attention to the role of viewers' moral judgments about media characters. Based on these judgments, positive affect is assumed to occur when "good" characters prevail, and when negative outcomes befall "bad" or disliked characters. Across a variety of genres, research has supported the assumption that viewers experience the greatest level of positive affect and enjoyment when the portrayed outcomes are perceived as just or correct (for an overview, see Raney \& Bryant, 2002).

Excitation transfer. The concept of excitation transfer (Zillmann, 1996) explains how negative affect experienced during suspenseful episodes when audiences are made to fear bad outcomes for liked characters can contribute to entertainment gratification, nevertheless. This concept assumes that residual arousal that stems from the experience of empathic distress can spill over, and can be reframed with positive thoughts and feelings when the suspenseful episode comes to a happy end. Thus, excitation transfer can give rise to euphoric feelings that are characterized by high levels of both arousal and positive valence.

Sensation seeking. The concept of sensation seeking (Zuckerman, 1979) is based on an arousal regulation framework as well. However, unlike theories of mood management and excitation transfer, it assumes that the excitement associated with novel, complex and intense sensations and experiences can be gratifying in its own right, that is, beyond an optimal level of arousal, and independent of positive valence. The strength of the sensation seeking motive has been related to specific patterns of media use including individuals' preference for violent 
and frightening content (see meta-analysis of Hoffner and Levine, 2005).

Meta-emotion. The gratification of feelings evoked by sad and tragic entertainment has been more puzzling to explain, specifically given the absence of just or happy endings. Oliver (1993) proposed an explanation based on the concept of meta-emotion (i.e., evaluative thoughts and feelings about emotions). For example, empathic sadness can be accompanied with positive feelings about the self because it is morally valued, especially as part of the female gender role. Based on this line of reasoning, Oliver (1993) predicted and found that "feelings of sadness elicited from viewing tearjerkers can be interpreted as pleasurable sensations among many viewers" (p. 336). A similar argument was made by Mills (1993) who interpreted the appeal of tragedy in terms of positive attitudes towards empathic sadness.

Mixed and meaningful affect. Recent research of Oliver and her colleagues (Oliver, 2008; Oliver, Limparos, Tamul, \& Woolley, 2009) has extended the scope of feeling qualities that may account for the appeal of tragic entertainment, highlighting the role of feelings such as tenderness (e.g., tender, kindly, understanding, sympathetic, warm) and meaningful affect (e.g., compassionate, inspired, introspective, and contemplative). Rather than sadness proper, these feelings seem to be characterized by the experience of mixed affect, that is, feeling happy and sad at the same time (cf., Larsen, McGraw, \& Cacioppo, 2001).

Though the appeal of sad content is still a matter of ongoing discussion, it seems safe to conclude at this point that in addition to the experience of pleasure and arousal, entertainment audiences can also be attracted by more complex feelings that involve some form of empathic sadness, either accompanied with mixed affect, or with evaluative components such as metaemotions, empathic attitudes, or meaningful affect.

\section{The Role of Emotional Entertainment Experiences in the Satisfaction of Social and}

\section{Cognitive Needs}

In addition to the immediate gratification obtained from rewarding feelings, different lines of research suggest that emotional media experiences may also be functional within the 
broader context of individuals' social and cognitive needs. Some of the theoretical mechanisms may be similar. For example, Reinecke and Trepte (2008) predicted and found that the effects of mood management can outlast media exposure and can improve subsequent task performance. Likewise, results of Appel (2008) suggest that the experience of poetic justice in fictional entertainment may serve not only to induce positive affect but also to strengthen individuals' belief in a just world. Other concepts have made the social and cognitive aspects of entertainment gratification their primary focus.

Relationship functions of entertainment. An early example of an approach that has linked emotional media experiences to social gratification is Zillmann, Weaver, Mundorf, and Aust's (1986) research on courtship functions of horror movies. These authors found that the enjoyment of horror films, and attractiveness ratings of cross-sex companions varied as a function of the companion's display of gender-typed behaviors such as male bravery and female squeamishness, suggesting that these behaviors serve as part of a courtship ritual that is gratifying for both partners. Research on the uses of television in general (Rubin, 1983), and among married couples in particular (Lull, 1990), has revealed relationship functions as well, including communication facilitation, affiliation, social learning, and role enactment.

Parasocial relationships. In addition to building and strengthening affective relationships with others, media-induced emotions can also serve to cultivate parasocial relationships with the characters, persons, or avatars on screen (Klimmt, Hartmann, Schramm, \& Vorderer, 2003; Rubin \& Perse, 1987). Unlike the premise of early theories such parasocial relationships do not seem to serve as a compensation for deficiencies in social life, but rather as a complementary source of social and emotional gratification (cf., Giles, 2002).

Vicarious Experiences. Concepts such as transportation (Green \& Brock, 2000), involvement (Vorderer, 1993), identification (Cohen, 2006), and narrative engagement (Busselle \& Bilandzic, 2009) have dealt with the gratification of making vicarious experiences. These concepts concur in assuming that viewers or readers of narrative media content tend to 
adopt the point of view of the characters, and to experience emotions from the characters' perspective. The primary focus of this line of research is on the role of vicarious experiences in mediating persuasion effects, but it has also been found that such experiences can contribute to entertainment gratification (Busselle \& Bilandzic, 2009; Green \& Brock, 2000).

Social comparison. The concept of downward social comparison (Mares \& Cantor, 1992) provides another example of how emotional media experiences can contribute to social and cognitive gratification. This concept assumes that rather than avoiding negatively valenced portrayals that remind them of their own problems, individuals may find comfort in such content, because it shows that others are worse off than the self.

Self-reflection. The reactive versus reflective model of aesthetic experience (Cupchik, 1994) broadens the scope of self-reflection beyond social comparison processes. This model highlights the role of emotional memories evoked by media content in creating aesthetic experiences that are both meaningful and enjoyable (for an overview, see Cupchik, 2011).

Eudaimonic motivation. A related type of entertainment experience that is focused on the experience of emotional meaning and contemplativeness has been conceptualized by Oliver (2008; Oliver \& Bartsch, 2010; Oliver \& Raney, 2011) based on the distinction in ancient philosophy between hedonic and eudaimonic happiness (Aristotle, trans. 1931). The concept of eudaimonic motivation assumes that in addition to hedonic motivations, media use can also be motivated by individuals' search for deeper insight, meaning, and purpose in life. For example, in a study on lessons learned from meaningful movies Oliver and Hartmann (2010) found that viewers reflected on the value and fleetingness of life, the importance of human virtue and endurance, and the inevitability of sadness, cruelty and pain as part of the human condition.

To summarize, entertainment research has accumulated an impressive body of evidence supporting the assumption that affective experiences can be gratifying for media users, including both the immediate gratification derived from rewarding feelings, and the more 
indirect but not less significant role of affect in the gratification of social and cognitive needs. Based on the research literature reviewed above, at least six theoretically distinct factors can be identified that seem to contribute to entertainment gratification. Three of the factors are related to the experience of emotions per se: 1) positive affect can clearly be gratifying, as assumed for example in theories of mood management and affective disposition; 2) arousal is an important theoretical element in models of mood management, sensation seeking, and excitation transfer; and 3) empathic sadness has been related to entertainment gratification in models of metaemotion, and empathic attitudes. The second set of gratification factors is related to social and cognitive processes that can be stimulated by emotional media experiences: 4) social relationship functions of shared emotions have been assumed with regard to courtship functions of horror films; 5) emotional engagement with characters is highlighted in models of affective disposition, transportation, involvement, identification, narrative engagement, and parasocial relationships; and 6) the role of emotions in stimulating (self-)reflection is emphasized in models of aesthetic experience, social comparison and eudaimonic gratification. Recent conceptualizations of entertainment as an intrinsically rewarding activity (Oliver \& Bartsch, 2010; Sherry, 2004; Tamborini, et al., 2010; Vorderer, Steen, \& Chan, 2006) have provided a useful and parsimonious formula that covers both aspects of entertainment gratification, that is, rewarding feelings as well as psychosocial functions of entertainment. Through the lens of an intrinsic motivation framework (cf., Csikszentmihalyi, 1990; Ryan, Huta, \& Deci, 2008), media experiences are entertaining to the extent that the affective, cognitive and social aspects of the experience are gratifying in and of themselves, independent of extrinsic rewards. Based on the research reviewed above, it seems that emotions can foster such intrinsically gratifying experiences in two ways, either because media-induced affect can make individuals feel better immediately (e.g., in terms of regulating mood and arousal), or because emotions can stimulate rewarding social and cognitive experiences that contribute to emotional well-being in more complex and sustainable ways 
(e.g., in that they promote a sense of meaning and social connectedness). This preliminary two-level model of emotional gratification in entertainment experience is displayed in Figure 1.

\section{Rationale of the Present Research}

The first type of entertainment gratification that is based on affect regulation is relatively well researched (for overviews, see Knobloch-Westerwick, 2006; Oliver, 2009; Vorderer, Klimmt, \& Ritterfeld, 2004), whereas evidence concerning the role of emotional entertainment experiences in the gratification of social and cognitive needs has only recently begun to emerge in a consistent manner (cf., Cupchik, 2011; Oliver \& Bartsch, 2010; Oliver \& Raney, 2011; Reinecke, Tamborini, Grizzard, Lewis, Eden, \& Bowman, in press; Tamborini et al., 2010; Vorderer \& Ritterfeld, 2009). The present research aims to advance this line of inquiry by providing a systematic assessment of gratifications that can be directly or indirectly associated with the experience of emotions in media use, and by analyzing how different kinds of emotions can contribute to different types of entertainment gratification.

To determine the most salient dimensions in individuals' experience of emotional gratification, a combination of qualitative and quantitative research methods was employed. During the first phase of the research, qualitative interviews were conducted to let respondents explain in their own words why it is gratifying for them to experience emotions in media use, and to sample natural language statements descriptive of such gratifications. In the second phase, a series of questionnaire studies was conducted using a pool of statements derived from the qualitative interviews. The questionnaire data were then used to analyze latent dimensions in individuals' self-report of emotional gratifications, to select items for scale construction, and to perform initial validation analyses concerning the relationship of these gratification factors with individuals' experience of emotions, and their evaluations of media content.

In terms of scale construction, the present research aims to provide a more fine-grained assessment of emotional gratification factors than that which is usually obtained in studies that cover the full range of gratifications associated with a given medium or program type. For 
example, only two of the six gratification factors in Conway and Rubin's (1991) study of TV gratifications are conceptually related to affective experiences, that is, entertainment and relaxation. The factor arousal in Rubin's (1983) initial work was not replicated in this later study that informed much of subsequent uses and gratification research. Likewise, results of early uses and gratification studies that revealed more serious gratification factors such as experiencing beauty and raising morale (Katz, Gurevitch, \& Haas, 1973), or self-development (Tesser, Millar, \& Wu, 1988) did not generate systematic follow-up research.

A recent set of scales to assess gratifying movie experiences developed by Oliver and Bartsch (2010) includes measures of fun, suspense, and appreciation (i.e., moving and thoughtprovoking experiences). This measure points to the utility of breaking down the general “entertainment" factor into qualitatively different facets of entertainment experience. Still, it leaves open important questions about the role of emotions in the gratification of social and cognitive needs. Apart from the reflective aspects of the appreciation factor, other types of social and cognitive gratifications such as character engagement, and social relationship functions of entertainment seem to be missing from the picture. Moreover, the nature of emotions that can stimulate reflective thoughts remains unclear, given that the appreciation scale was not consistently related to measures of affective valence and arousal. Recent work of Oliver et al. (2009; Oliver \& Hartmann, 2010) suggests that reflective entertainment experiences are often associated with mixed emotions of both positive and negative valence, which might explain the inconsistent findings that were obtained by Oliver and Bartsch, (2010) using basic measures of valence and arousal.

A more systematic assessment of entertainment gratifications that can directly arise from, or be stimulated by the experience of emotions is of both theoretical and methodological interest. In particular, the two-level model of emotional gratification in entertainment experience outlined above highlights the role of social and cognitive gratifications such as individuals' sense of meaning and social connectedness that contribute to personal and 
emotional well-being beyond short-term mood regulation. To arrive at a more comprehensive understanding of the appeals and functions of entertainment media, it is vital to enhance the detail with which these aspects of entertainment experience can be measured and described.

Based on the theoretical and methodological considerations outlined above, an affectcentered approach to entertainment gratification was chosen that covers both rewarding feelings, and the role of emotions in the gratification of social and cognitive needs. This is not meant, of course, to deny the possibility that other types of gratification that are unrelated to emotions may also contribute to entertainment experience. Rather, the focus on affective factors serves to zoom in on one of the most important theoretical elements in entertainment research and to advance the level of detail with which we can assess its gratification potential.

\section{Qualitative Interview Study (Study 1)}

To revisit and broaden the scope of theoretical assumptions about the role of emotions in entertainment gratification, qualitative interviews were conducted concerning individuals' experiences of movies. Maximum variation sampling (Patton, 2002, p. 243) was employed to recruit an interview sample with a heterogeneous distribution of age, gender and genre preferences. Sampling was guided by a combination matrix of three age groups (under 25, 2550, over 50), four genre preferences (comedy, drama, action, and horror), and the two genders. For each combination of age and genre preference at least one male and one female respondent were interviewed. This sampling scheme includes participants with genre preferences that are typical of their age and gender (e.g., young men with comedy or action preferences) as well as participants with less typical genre preferences (e.g., women over 50 with action or horror preferences). Untypical cases were purposely included to broaden the spectrum of movie experiences and gratifications discussed in the interviews.

Twenty-eight German-speaking participants (14 male, 14 female) who were 18 to 70 years old $(M=37.82, S D=17.49)$ took part in the interview study and were paid a small fee for their participation. The interviews were semi-structured and lasted about 40 to 60 minutes. 
Respondents were asked to think of a movie of their preferred genre that they liked and could vividly recall. First, the interviewer asked them to describe one of their favorite scenes in the movie they named. Then respondents were asked about the emotions they experienced during the film scene, whether they liked these emotions, and if so, why. Subsequently, participants were asked to name other emotions that they experienced during the movie and to answer the same questions. During the first phase of the interview the interviewer tried to elicit as many spontaneous statements about emotional gratifications as possible by asking participants to name and evaluate film-related emotions and to explain their evaluation. In the second phase of the interview, more specific theory-guided questions were used to provide impulses for further discussion of emotional gratifications. These questions were related to 1) the experience of emotions per se, including physiological responses, subjective feelings, and absorption, and 2) the perceived function of film-related emotions in participants' emotional lives including coping with distressing emotions, character engagement, social functions of emotions, and self-reflection.

The interviews were taped and fully transcribed. Qualitative data analysis proceeded through three stages. In a first step, short interpretations of about one page were written that summarized the interviewees' account of why it was gratifying for them to experience emotions when watching movies. For each interview, two summaries were written, one by the interviewer, and one by another researcher. Based on the short interpretations, inductive category development (Dey, 1993; Miles \& Huberman, 1994) was used to form categories of similar statements. Third, exploratory coding was applied to half of the interviews to evaluate the comprehensiveness of the category system and to guide its revision. Categories with frequent overlap in the exploratory coding results were collapsed, and new categories were created for statements that did not fit into the categories. The final set of categories included 66 types of statements about emotional gratification in film viewing.

Based on the qualitative analysis of the interviews and the exploratory coding results, 
an item-pool was constructed for the subsequent questionnaire studies. Eighteen categories of statements that occurred most frequently were represented by two items each and 48 categories of statements that occurred less frequently were represented by one item each. Thus, the initial item-pool included a total of 84 statements about emotional gratification in film viewing.

\section{Scale Development and Initial Validation Analyses (Studies 2 and 3)}

To follow up the qualitative interview results, three questionnaire studies were conducted that involved different samples and rating tasks. In Study 2, a sample of students and students' relatives were asked to name and rate a movie that they liked and could vividly recall, so as to frame the rating task in a way that was similar to the qualitative interviews. In Study 3, a sample of video rental customers rated the movie they had rented after watching it at home, thus providing ratings of emotional gratification under the immediate impression of the movie in a naturalistic viewing situation. In Study 4, users of TV series portals on the internet rated their favorite TV series, thus extending the results to a different entertainment medium.

The purpose of Studies 2 and 3 was to explore the dimensionality of emotional gratification in film viewers, to select items for scale construction, and to conduct initial validation analyses. The validation criteria were based on the theoretical background outlined above and reflected the following assumptions:

1. The concept of emotional gratification implies that emotions are critically involved in the gratifying experience (either because of rewarding feelings, or because of their functionality with regard to the gratification of social and cognitive needs); therefore, measures of emotional gratification should be related to individuals' self-report of emotions.

2. The concept of emotional gratification implies that the emotional experience is perceived to be gratifying; therefore, measures of emotional gratification should be related to individuals' self-report of positive meta-emotions.

3. Gratification obtained from the experience of emotions in media use should lead to a 
more positive evaluation of the emotion-eliciting media content; therefore, measures of emotional gratification should be related to positive content evaluation.

Based on these considerations, all three validation criteria had to be met by a potential "emotional gratification factor" to be considered for scale development. To be able to evaluate whether the criteria were met across different types of entertainment audiences, the film genre and sociodemographic information were assessed and used as control variables.

\section{Method}

Participants and Procedure Study 2. Study 2 involved a sample of German students $(N=154 ; 75$ male, 79 female; age: $20-29, M=23.44, S D=2.06)$ and students' relatives age 50 and over $(N=77 ; 38$ male, 39 female, age: 50-80, $M=59.78, S D=7.92)$ who rated a movie from memory using a paper and pencil questionnaire. The students took the questionnaire home and had it completed by their relatives during the Christmas holidays. Those who successfully invited relatives participated in a lottery for gift certificates.

Participants and Procedure Study 3. In Study 3, 294 video rental customers (148 male, 142 female, and 4 who did not report their gender; age $18-78, M=31.90, S D=11.79$ ) completed a questionnaire about their experiences of the movie they had rented. Participants were invited using posters attached near the cash desks of two video rental shops in Germany. The questionnaires and a leaflet explaining the procedure were handed out at the cash desk to those who were interested to participate in the study. The leaflet asked participants to take the questionnaire home with them, to complete it immediately after watching the rented movie, and then to return it to the shop assistant when returning the DVD. Those who returned the completed questionnaire were reimbursed the rental fee for the movie for up to two days.

\section{Measures}

Genre and general evaluation of the movie. In Study 2 the questionnaire asked participants to think of and name a movie that they liked and could vividly recall. In Study 3 participants were asked to name the rented movie they had just seen on DVD. Then 
participants were asked to indicate the genre of the movie, and to rate their impressions of the movie. To indicate the film genre, participants were asked to select one or more of the following categories that were based on the genres mentioned most frequently in the interview study: comedy, drama, action, thriller, horror, and documentary, or to name other genres using a text field. Further, participants were asked to rate the movie using four items expressive of general evaluation criteria: "The movie was really good," "The movie was entertaining," "I found the movie artistically valuable," and "The movie left me with a lasting impression."

Emotions and meta-emotions. Next, the questionnaire asked participants to think of the feelings they experienced while watching the movie, and to name these feelings. Then, they were asked to rate the feelings experienced during the movie using the valence and arousal scales of the Self Assessment Manikin (SAM, Lang, 1980). In Study 2, the SAM was followed by the Positive and Negative Affect Schedule (PANAS, Watson, Clark, \& Tellegen, 1988). In Study 3, ten discrete emotions were assessed using the Modified Differential Affect Scale (MDAS, Renaud \& Unz, 2006): joy, amusement, interest, surprise, fascination, poignancy, sadness, anger, fear, and disgust. Finally, participants were asked to rate their meta-emotions (i.e., their feelings about the emotions experienced during the movie). Meta-emotions were assessed using the following items: "I like this feeling," "When I am in this mood I enjoy it," and "It was pleasant for me to experience these feelings."

Emotional gratifications. The main part of the questionnaire included 84 statements derived from the qualitative interviews. The semantic structure of these items was based the logic of interview statements that link an evaluative statement about emotions experienced during media exposure with a specific reason for this evaluation. The first half-sentence was identical for all items: "It was good to experience these feelings, ..." whereas the second halfsentence was different for each item, for instance: “... because I enjoy the thrill of it," or “... because it makes me think about myself." Participants were asked to indicate how well each statement describes their experience of the movie they had named. 
Responses to the movie evaluation, meta-emotion, and emotional gratification items were recorded on 5-point Likert scales ranging from 1 (strongly disagree) to 5 (strongly agree). Emotion items were recorded a 5-point scale ranging from 1 (not at all) to 5 (very much). Valence and arousal were assessed using the 5-point pictorial rating scales of the SAM (Lang, 1980). At the end of the questionnaire, participants were asked to provide basic demographic information (age, gender and education).

\section{Results}

To examine underlying dimensions of emotional gratification, exploratory factor analyses were performed on the initial item pool of 84 items. In all of the following analyses, principal components analyses with varimax rotation was used. Factor analysis results for Studies 2, 3 and 4 are summarized in Table 1. This table includes eigenvalues and variance explained by each factor in Studies 2, 3 and 4, as well as reliabilities and descriptive statistics for the items selected for scale construction. Factor loadings of the scale items displayed in Table 1 are based on the final exploratory and confirmatory factor analyses in Study 4.

\section{Exploratory Factor Analyses}

Exploratory Factor Analysis Study 2. The first set of analyses was performed on the data set of students and students' relatives who had rated a movie from memory. An initial analysis revealed 17 factors with eigenvalues greater than 1 that accounted for $71 \%$ of the variance. The first seven factors were readily interpretable in that they featured a substantial number of semantically related items loading on each factor. The remaining factors were difficult to interpret, however, given that no more than one or two items had primary loadings on these smaller factors with eigenvalues less than 2 . Besides the theoretically expected factors, an additional factor emerged that was related to the vicarious release of emotions that have no room in everyday life. The first seven factors could be interpreted as follows (with the highest loading item on each factor in parentheses):

1. Contemplative emotional experiences (“...because it makes me think about myself.”) 
2. Fun (“... because it amuses me.”)

3. Thrill (“... because I enjoy the thrill of it.”)

4. Emotional engagement with characters (“... because I like to feel with characters.”)

5. Vicarious release of emotions (“... because I cannot act on these feelings in everyday life.")

6. Empathic sadness (“... because I like to have a good cry.”)

7. Social sharing of emotions (... because it inspires me to talk about the movie with others.")

To follow up the stability of these factors, additional analyses were run requesting six, seven, or eight factors. The seven-factor solution explained $55 \%$ of the variance, and reproduced the first seven factors of the initial 17-factor solution. When the number of factors was constrained to six (i.e., the number of theoretically expected dimensions), the unexpected factor vicarious release of emotions remained stable, whereas the expected factor social sharing of emotions dropped out. Thus, constraining the number of factors to less than 7 did not seem indicated against the background of theoretical assumptions. Including more than seven factors did not seem to be indicated either. In the eight-factor solution, the seven factors described above remained stable, and only two items with loadings $<.60$ loaded on the eighth factor.

Exploratory Factor Analysis Study 3. To further evaluate the robustness of the factor structure revealed in Study 2, additional analyses were conducted using the second data set of video rental customers who rated the movie immediately after watching it at home. In an initial analysis, 17 factors with eigenvalues greater than 1 emerged that explained $67 \%$ of the variance. When the number of factors was constrained, a similar factor structure emerged as in Study 2. However, vicarious release of emotions did not form an independent factor in the seven-factor solution, and the seventh factor was composed of only one item. The six-factor solution including contemplative experiences, fun, thrill, character engagement, empathic 
sadness, and social sharing of emotions explained $50 \%$ of the variance.

Joint Factor Analysis of Studies 2 and 3. To follow up the results of Study 3 that raised doubts about the robustness of the vicarious release factor, a joint factor analysis of both data sets was performed. Vicarious release of emotions emerged clearly in the 7-factor solution that explained $51 \%$ of the variance. Therefore, this factor was considered further for scale development. Table 1 shows the eigenvalues and the percentage of variance explained by each factor as well as reliability estimates and descriptive statistics for the scales developed to represent these factors.

Scale construction. For each of the seven dimensions, four items were selected for scale construction. Selection criteria were high and unambiguous factor loadings in the 7factor solution, good scale statistics in terms of reliability estimates and inter-item correlation, and low redundancy in the wording of the items. In the case of the vicarious release factor, only the three highest loading items met the criteria, whereas the remaining items lowered the reliability estimate of the scale using Cronbach's alpha. In terms of empathic sadness, only two items met the criteria for the same reason.

Validation Analyses. To provide an initial assessment of validity, a series of regression analyses was performed on the combined data set (Studies 2 and 3). Specifically, the analyses considered how emotional gratification ratings are predicted by individuals' experience of emotions and meta-emotions, and how they predict different aspects of movie evaluation. The rating task, the genre of the movie, age, gender, and education were considered as control variables. In addition, correlations of the scales with a set of more finegrained emotional self-report measures including the PANAS and MDAS scales were analyzed.

Data preparation. To prepare the data for these analyses, the following variables were coded: Dummy codes were created for gender (males, $N=261$ vs. females, $N=260$ ), and for the rating task (those who rated the movie after watching it on DVD, $N=294$ vs. those who 
rated a movie from memory, $N=231$ ). Two age groups were coded: Young adults (age 18-25, $N=245$ ), and older adults (age 50 and above, $N=113$ ), with the group of 26 to 49 year olds ( $N$ $=161$ ) serving as the reference category. In terms of education, two categories were coded: general education (participants who were enrolled in or graduated from some form of mandatory school education), and higher education (participants who were enrolled in or graduated from non-mandatory forms of academic high school, college or university education). Due to the sample of students and students' relatives in Study 2, the higher education group $(N=399)$ was over-represented compared to the basic education group $(N=$ 116).

In terms of film genre, a simplified genre variable was created based on three broad categories of film genres that have been identified by Hall (2005): light genres (comedy), serious genres (drama, documentary), and action oriented genres (action, thriller, horror). The simplified genre variable was coded only if participants' genre ratings identified their film as representing one of the three genre types, and if no genres from the respective other categories were selected. Of the 525 participants, 384 met the criteria for coding this simplified genre variable, with 115 "pure" cases of light films (comedies), 115 serious films (drama and/or documentary), and 154 action-oriented films (action and/or thriller and/or horror). The remaining 141 cases of participants who selected mixed genres were used as the reference category in this analysis, given that an inspection of the genre ratings in this group revealed a relatively balanced distribution of genres (58 participants in this group selected comedy, 62 drama, 12 documentary, 37 action, 21 thriller, and 7 horror).

Concerning the emotion variables, reliability estimates indicated that the scales used to assess emotions and meta-emotions were internally consistent in terms of Cronbach's alpha: PANAS (positive affect: $\alpha=.80$; negative affect: $\alpha=.87$ ); MDAS (joy: $\alpha=.95$, amusement: $\alpha$ $=.92$, interest: $\alpha=.81$, surprise: $\alpha=.84$, fascination: $\alpha=.81$, poignancy: $\alpha=.80$, sadness: $\alpha=$ .72 , anger: $\alpha=.92$, fear: $\alpha=.82$, disgust: $\alpha=.92$.), and meta-emotions $(\alpha=.90)$. 
Regression analyses to predict emotional gratification ratings. First, a series of hierarchical regression analyses was performed with each of the emotional gratification scales as the dependent variables and the following predictors: In the first step the dummy code for the rating task was entered. The dummy codes for light, serious, and action-oriented genres were entered in the second step. In the third step the dummy codes for the two age groups, gender, and education were entered. In the fourth and final step, SAM arousal and valence scores were entered together with meta-emotions. Table 2 shows the regression weights for each of the variables at the step they were entered.

The influence of film genres showed a pattern that was expected and in line with earlier research (cf., Oliver \& Bartsch, 2010): Light films were associated with fun, action-oriented films were associated with thrill, and serious films were associated with sad and contemplative experiences. In terms of individual differences, females reported higher levels of empathic sadness and social sharing of emotions than males. Older adults reported higher levels of contemplative experiences, and reported lower levels of fun, thrill, and empathic sadness (i.e., the three gratification factors related to rewarding aspects of moods and emotions per se). Only one of the emotional gratification factors was influenced by education: Participants with higher education reported lower levels of vicarious emotional release.

The final step of the regression equation revealed that ratings on each of the seven emotional gratification scales were significantly predicted by the emotional arousal and/or valence scores of the SAM, and by positive meta-emotions. Specifically, fun was predicted by positive valence. All other scales were predicted by arousal. In addition, contemplative experiences were predicted by negative valence. Moreover, ratings on all emotional gratification scales were predicted by positive meta-emotions.

Regression analyses of emotional gratifications as predictors of movie evaluation. A second series of hierarchical regression analyses was conducted to assess the predictive validity of the emotional gratification scales concerning individuals' general evaluation of the 
movie in terms of entertainment value, perceived artistic quality, lasting impression, and generally positive evaluation. Again, the rating task, the genre of the movie, and participants' age, gender and education were used as control variables. Each emotional gratification scale was entered in the last step of a separate regression equation to predict the movie evaluation variables. The regression weights and increments in the final step of each equation are displayed in Table 3. As this series of analyses revealed, all of the seven emotional gratification scales predicted individuals' agreement with the statement "the movie was really good." In addition, fun, thrill, and character engagement predicted agreement with "the movie was entertaining." Contemplativeness, character engagement, and social sharing of emotions predicted agreement with "I found the movie artistically valuable." Finally, contemplativeness, character engagement, social sharing and vicarious release of emotions predicted agreement with the statement "the movie left me with a lasting impression."

Correlation of emotional gratification ratings with positive and negative affect. To follow up the association of emotional gratification ratings with audience emotions, correlations of the scales with a set of more fine-grained self-report measures of emotion were analyzed. A first analysis considered correlations of emotional gratifications with the PANAS scale (Watson, et al., 1988). In contrast to the SAM that treats positive and negative affect as opposite ends of a continuum, the PANAS scale considers positive and negative affect as orthogonal dimensions. This additional measure was included in Study 2 to account for the possibility that positive and negative affect can be experienced simultaneously in entertainment experience (cf., Oliver et al., 2009). In accord with the theoretical construct, the PANAS scales were uncorrelated to each other $(r=.08, \mathrm{p}>.10)$. As shown in Table 4 , all emotional gratification scales except vicarious release of emotions were associated with positive affect. In terms of negative affect, fun was negatively related, whereas empathic sadness, contemplativeness, and vicarious release were positively related. Of note, empathic sadness and contemplativeness were positively related with both PANAS scales, indicating that these 
gratifications are associated with the experience of both positive and negative affect.

Discrete emotions. In Study 3, respondents' self-report of ten discrete emotions was assessed using the MDAS scale (Renaud \& Unz, 2006). Previous research using this scale (Bartsch, Appel, \& Storch, 2010) has found three main factors in individuals' report of MDAS emotions: positive emotions (joy, amusement), negative emotions (sadness, anger, fear, disgust), and ambivalent emotions (interest, surprise, fascination, poignancy). This broad factor structure of the MDAS accounted for $61 \%$ of the variance in the data. However, to explore the possibility of more fine-grained patterns of correlations, the correlation of the emotional gratification scales with each of the MDAS subscales were separately analyzed. As shown in Table 4, all emotional gratification scales were significantly related to the experience of discrete emotions. The fun scale was positively correlated with the two positive emotions, and was negatively related with the four negative emotions, and with poignancy. Thrill was positively related to all positive and ambivalent emotions, and was negatively related to sadness. Empathic sadness was positively related to sadness and poignancy. Contemplativeness was positively related to all negative and ambivalent emotions. Character engagement was positively related with all positive and ambivalent emotions, and with sadness. Social sharing of emotions was positively related to all ambivalent emotions, and to three of the negative emotions: sadness, anger, and fear. Finally, vicarious release of emotions was positively related to fascination, poignancy, sadness, fear, and disgust.

\section{Scale Revision and Validation (Study 4)}

Study 4 served to confirm the dimensional structure of the scales using a confirmatory factor analysis approach, and to extend the validation analyses to a different entertainment medium, that is, TV series. Furthermore, Study 4 was used to revise the scales, and to complement the two subscales that included less than four items.

\section{Method}

Participants and Procedure Study 4. Three hundred and ninety-three users of 
German-speaking TV serial portals on the internet (273 male, 120 female; age 18-50, $M=$ 23.70, $S D=5.75$ ) participated in an online survey about TV series. Participants were invited using news postings on three different TV series portals that included a link to the online survey. Those who completed the online survey participated in a lottery for gift certificates.

Measures. Participants were asked to name and rate their favorite TV series. To indicate the genre of the series, participants were asked to select one or more of the following genre labels: comedy, drama, soap, action, crime and sci-fi/fantasy. Participants' self-report of typical emotions experienced when watching the TV series was assessed using the valence and arousal scales of the SAM and the meta-emotion items as in Studies 2 and 3. Then participants rated their experience of the TV series using the revised set of 28 emotional gratification items (see Table 1). Finally, basic demographic information (age, gender and education) was assessed. Evaluation of the TV series was not assessed in this study, because the rating task asked participants to rate their favorite TV series. Therefore, a ceiling effect for positive evaluation was to be expected.

\section{Results}

Exploratory and confirmatory factor analyses. To validate the factor structure of the scales obtained in Studies 2 and 3, exploratory and confirmatory factor analyses were performed. First, a principal components analysis with varimax rotation was performed on the revised set of 28 items. Seven factors with eigenvalues greater than 1 emerged in this analysis that explained $68 \%$ of the variance. All primary loadings of the scale items were as expected. Next, a confirmatory factor analysis was conducted using AMOS with maximum likelihood estimation. This analysis revealed an acceptable fit, $\chi 2 / \mathrm{df}=2.14, \mathrm{CFI}=.93, \mathrm{RMSEA}=.05$, 90\% CI RMSEA: .05-.06).

Regression Analyses. To follow up the results of Studies 2 and 3, a series of hierarchical regression analyses was performed to predict ratings on the seven emotional gratification scales using the following predictors: In the first step, dummy codes were entered 
for the series rated. Two series were particularly popular among the sample: 94 participants rated Prison Break, and 117 rated The Simpsons. The remaining 182 participants rated a heterogeneous mix of different series and genres (82 comedy ratings, 90 drama, 59 scifi/fantasy, 38 action, 19 crime, 15 soap). Given the relatively balanced distribution of light, serious and action-oriented genres, this group was used as the reference category. In the second step, participants' age and the dummy codes for gender and educational level were entered (cf., the coding scheme in Studies 2 and 3). In the third step, the SAM arousal and valence scores were entered together with the mean score for meta-emotions. Table 5 shows the regression weights for each of the predictor variables at the step they were entered.

The regression results revealed the following pattern of influence for the individual difference variables: The age differences observed in Studies 2 and 3 were not replicated, except for the finding that older participants scored higher on contemplative experiences. This is not surprising, given that the sample was rather young (age 18-50; $M=23.70 ; S D=5.75$ ), and because the age group over 50 that accounted for the differences in Studies 2 and 3 was not represented in this sample. As in Studies 2 and 3, females scored higher on moving experiences than males did. In terms of education, there was a relatively balanced distribution of educational levels this time (basic education: 177; higher education: 208). It is remarkable, therefore, that the pattern of influence was exactly the same as in Studies 2 and 3: Vicarious release of emotions was the only gratification factor that was influenced by education.

The final step of the regression equation considered the influence of emotional arousal, valence, and meta-emotions as predictors of emotional gratification ratings, with the series rated and individual differences in age, gender, and education as control variables. The pattern of results was similar to that obtained in Studies 2 and 3. Fun ratings were predicted by positive valence, whereas all other scale ratings were predicted by arousal. However, unlike the results of Studies 2 and 3, contemplative experiences were not predicted by negative valence. The association of the scales with positive meta-emotions was replicated, except for social 
sharing of emotions which was not significantly predicted by meta-emotions in this study. However, given that the trend was in the expected direction, and because ratings on the social sharing scale were predicted by positive meta-emotions in Studies 2 and 3, this factor was kept.

\section{Discussion}

A series of qualitative and quantitative studies was conducted to extend research on the role of emotions in entertainment experience. Specifically, the present research aimed to provide research tools for a systematic assessment of two types of gratification factors that can be associated with the experience of emotions: On the one hand, the experience of emotions per se can be gratifying. On the other hand, emotional media experiences can also contribute to the gratification of individuals' social and cognitive needs. The results suggest that both kinds of emotional gratification factors are salient in individuals' experience of movies and TV series, and that they can be assessed introspectively using a set of short and reliable scales. The scales developed to measure these gratifications were systematically related to the validation criteria including the experience of emotions and meta-emotions, as well as different aspects of positive content evaluation.

Exploratory factor analyses of a pool of statements derived from qualitative interviews revealed a set of seven factors in individuals' self-report of emotional gratifications. The factor structure proved to be robust in the confirmatory factor analysis performed in Study 4 concerning individuals' experience of TV series. Among the seven factors that emerged from the data, three factors were related to the appeal of specific feelings: 1) fun, 2) thrill, and 3) empathic sadness. The factors fun and thrill seem to reflect such well-researched entertainment gratifications as mood-management (Zillmann, 1988), and sensation seeking (Zuckerman, 1979), whereas the factor empathic sadness draws attention to more complex forms of affect regulation that cannot be explained in terms of positive valence and arousal alone. Rather, the appeal of empathic sadness seems to involve evaluative components such as attitudes towards empathy, or meta-emotions that merit further theoretical and empirical attention (Oliver, 1993; 
Oliver et al., 2009; Mills, 1993).

The present results suggest that the experience of being "overwhelmed with emotion" or having "a good cry" can be gratifying per se, independent of additional social and cognitive gratifications that can also be associated with sad entertainment, such as contemplative experiences for example. In line with the empirical distinctiveness of the empathic sadness factor in this study, follow-up research (Bartsch, in press) indicates that empathic sadness and contemplativeness are independent predictors of positive content evaluation. But clearly more research is needed to further explore the direct vs. indirect gratifications that can be associated with empathic sadness.

Four additional factors were related to the role of emotions in the gratification of social and cognitive needs: 4) contemplative emotional experiences, 5) emotional engagement with characters, 6) social sharing of emotions, and 7) vicarious release of emotions. This second type of emotional gratification factors was the main focus of this study, given that social and cognitive functions of entertainment are less well researched than affect regulation functions.

One notable exception is the factor character engagement that has received extensive research coverage in terms of parasocial relationships (Rubin \& Perse, 1987), and vicarious experiences such as transportation (Green \& Brock, 2000), identification (Cohen, 2006), involvement (Vorderer, 1993), and narrative engagement (Busselle \& Bilandzic, 2009). Research of Hoffner (1996) suggests that substantial overlap occurs among the factors that account for identification and parasocial interaction with TV characters, which is consistent with the emergence of a single character-related factor in this study. Nevertheless it is important to note that more fine-grained theoretical frameworks and operationalizations have also been developed that distinguish between identification and dyadic concepts such as parasocial relationships (Klimmt, Hefner, \& Vorderer, 2009; Klimmt, Hefner, Vorderer, Roth, $\&$ Blake, 2010). Thus, to follow up the present results, more detailed research into the emotional gratifications associated with different types of character engagement is needed. 
Compared to the extensive research on character engagement, social relationship functions of entertainment have received much less attention (but see, Lull, 1990; Zillmann et al., 1986). The factor social sharing of emotions that emerged in this study highlights the role of emotions in stimulating rewarding experiences of communication and sociability among entertainment audiences. Thus, despite a long-standing theoretical fascination of entertainment research with parasocial relationships and other forms of character engagement, social relationship functions such as the opportunity to share emotions with family, friends, or romantic partners should not be overlooked as a motivation for entertainment use. In particular, entertainment research could profit from a theoretical integration of this emerging research topic with research on social sharing of emotions in social psychology (for an overview see, Rimé, 2007), and in news diffusion studies (Hoffner, Fujioka, Ibrahim, \& Ye, 2002; Ibrahim, Ye, \& Hoffner, 2008). Both lines of research highlight the role of emotions in stimulating interpersonal communication, and draw attention to positive outcomes of social sharing in terms of emotion regulation, personal well-being, and social cohesion. Further research is warranted to elucidate the possible contribution of entertainment to these kinds of positive social and personal outcomes.

In addition to social and parasocial relationship functions, the factor contemplative emotional experiences highlights the relevance of another emerging research topic, that is the role of entertainment in stimulating rewarding cognitive experiences (cf., Cupchik, 2011; Oliver \& Bartsch, 2010; Oliver \& Raney, 2011; Vorderer \& Ritterfeld, 2009). This factor is akin to the "appreciation" factor in Oliver and Bartsch's (2010) research that is characterized by meaningful, moving, and thought-provoking experiences. The present results provide further insight into the types of emotions that can stimulate such a sense of reflectiveness among movie and TV audiences: Contemplative entertainment experiences were related to a broad spectrum of emotions with negative or mixed affective valence, including interest, surprise, fascination, poignancy, sadness, anger, fear, and disgust. This pattern of findings is 
consistent with Oliver and Bartsch's (2010) observation that the experience of appreciation was not confined to the tear-jerker genre. Light and action-oriented films, although lower on ratings of appreciation than dramas, were not devoid of appreciation. The present results provide further clarification by distinguishing between the gratification derived from specific feelings associated with the tear-jerker genre (i.e., sad and poignant feelings), and the cognitively stimulating function of negative and mixed emotions that include but are not limited to sadness and poignancy.

Finally, vicarious release of emotions emerged as an unexpected factor. This factor is reminiscent of Aristotle's idea of catharsis (cf., Feshbach \& Singer, 1971) that has become widely rejected in the face of evidence indicating that exposure to media violence tends to increase rather than decrease aggressive cognition and behavior (see overview of Bushman \& Huesmann, 2000). Interestingly, however, this factor was not related to the experience of anger. Rather, vicarious release was correlated to a set of "weak" or "vulnerable" emotions including sadness, fear, disgust, fascination and poignancy. Thus, instead of venting aggression, this factor might reflect individuals' owning up to vulnerabilities that they avoid admitting in everyday life. Therefore, entertainment research could profit from revisiting the concept of catharsis with regard to other emotions than just anger and frustration.

Despite the qualitative differences between the four social and cognitive gratification factors, there are also important similarities. These similarities might best be described in terms of a sense of meaning and social connectedness that individuals seem to seek in entertainment. Recent developments in entertainment theory (Oliver \& Raney, 2011; Reinecke et al., in press; Tamborini et al., 2010; Vorderer \& Ritterfeld, 2009) have begun to incorporate these types of psychosocial needs by linking entertainment research with research on psychological well-being. Different concepts have been adopted in this context, including lower order vs. higher order needs (Maslow, 1943), subjective vs. psychological well-being (Keyes, Shmotkin, \& Ryff, 2002), and hedonic vs. eudaimonic well-being (Ryan, Huta, \& 
Deci, 2008; Waterman, 1993). What these conceptual frameworks have in common is the assumption of more complex psychosocial needs that cannot be reduced to hedonic affect regulation. For example, self-determination theory (Ryan et al., 2008) assumes that eudaimonic well-being arises from the satisfaction of individuals' needs for autonomy, competence, and relatedness. In addition, the concept of psychological well-being (Keyes et al., 2002) proposes six domains of well-being that include and extend these self-determination needs: autonomy, environmental mastery, positive relations with others, personal growth, purpose in life, and self-acceptance.

This framework of eudaimonic and psychological well-being provides an overarching interpretation for the social and cognitive gratification factors that emerged in this study: Social sharing of emotions and character engagement are linked to relatedness needs. Vicarious release of emotions can satisfy autonomy needs. Finally, contemplative entertainment experiences can be interpreted in terms of individuals' search for self-acceptance, purpose in life, and personal growth. In each case, entertainment media seem to provide a low-risk opportunity for the fulfillment of psychological needs. For example, character engagement can foster a sense of relatedness without the risk of social rejection. Likewise, thinking or talking about a movie character can offer a face-saving opportunity to think or talk about the self. By providing such opportunities for the satisfaction of psychosocial needs, entertainment can contribute to a sense of eudaimonic well-being that goes beyond short term affect regulation.

\section{Limitations and Outlook}

The framework of eudaimonic and psychological well-being can also be useful in drawing attention to the limitations of the present research. What seems to be absent from the picture is the need for competence and environmental mastery. Contemplative entertainment experiences may partly account for the need to master cognitive challenges. However, the experience of competence and mastery in other domains such as motor skills or interactive problem solving is not covered by these scales. This limitation clearly results from the focus 
on non-interactive entertainment media such as movies and TV series. Studies on need satisfaction in the context of interactive entertainment (Reinecke et al., in press; Tamborini et al., 2010) have found that mastering the challenges presented in video games can satisfy individuals' needs for competence and autonomy, which in turn leads to greater enjoyment of the game. It is therefore important to keep in mind that interactive entertainment can satisfy intrinsic needs and promote psychological well-being in ways that are not covered by the present scales.

Another limitation lies in the descriptive and correlational approach of this study that does not allow for causal conclusions. Findings concerning the dual function of emotional entertainment experiences in affect regulation and psychosocial well-being must therefore be interpreted with caution. In the case of some gratification factors including fun, thrill, empathic sadness, and character engagement, explanatory interpretations are unproblematic, because experimental evidence is available that supports participants' introspective account of emotional gratifications (see literature review above). For the remaining social and cognitive gratification factors, however, explanatory evidence is scarce (in the case of social sharing), lacking (in the case of contemplative experiences), or seemingly contrary (in the case of vicarious release). With regard to these factors, the present findings can pave the way for explanatory follow-up research by providing descriptive evidence that specifies the types of rewarding social and cognitive experiences that individuals seem to seek in entertainment, and the types of emotions that may be relevant in stimulating these experiences. Nevertheless it would be premature to draw conclusions about the causal effects implied in statements such as: "it was good to experience these feelings, because it makes me think about myself," or "...because it inspires me to talk about the movie with others." At this point, the reverse causation model cannot be ruled out, that is, emotions could be outcomes rather than antecedents of rewarding social and cognitive processes such as character engagement, selfreflection or talkativeness (cf., Cohen, 2006; Klimmt, Hartmann, \& Schramm, 2006). Further 
experimental research is needed to determine whether the influence of emotions on rewarding social and cognitive processes is in line with the present model, reversed, or bidirectional. Of note, bidirectional models assuming a mutually reinforcing interaction between emotion and cognition in entertainment experience would be fully compatible with the present argument that emotions can have a stimulating influence on social and cognitive gratification factors.

A final and related caveat concerns the introspective assessment of emotional gratifications. The formulation of scale items follows the logic of the uses and gratifications approach that focuses on individuals' subjective reasons and motivations for media use - in this case the reasons why emotional media experiences are perceived to be gratifying. This focus on subjective reasons (as expressed by the conjunction "because") has methodological advantages as well as drawbacks. On the one hand, the conjunction of emotions with different appeals and functions of entertainment is essential to the concept of emotional gratification, and should therefore be covered by an introspective measure. Moreover, in the case of the present study, the use of a semantic structure that was similar to the interview statements was functional because it provided a direct follow-up of the qualitative results. With the added advantages of large samples and quantitative data analysis, the qualitative results could be winnowed for categories of statements that were plausible and meaningfully related in the perception of larger samples of movie and TV audiences. This type of analysis is important to arrive at a more comprehensive understanding of individuals' subjective reasons for seeking out emotional entertainment experiences - which in turn can be helpful to identify possible motivations that have not been sufficiently covered in entertainment theory and research.

It is important to keep in mind, however, that subjective reasons are not the same as causal evidence, and that different types of measures are needed in each case. In their current form the scale items conflate different conceptual components that together constitute emotional gratifications, including emotions, positive evaluations of the emotions, and specific reasons for these evaluations (such as rewarding feelings, or rewarding social and cognitive 
experiences). In order to move from a descriptive approach to an explanatory approach that examines the interrelationship among these conceptual components, the scale items need to be broken down to a set of independent measures. For example, to follow up the processes involved in contemplative entertainment experiences, emotions and reflective thoughts need to be assessed as separate variables, so as to be able to analyze the influence of emotions on reflective thoughts, and the influence of both on variables such as content evaluation or selective exposure that can serve as independent indicators of gratifications obtained. The scale items can be adapted for this kind of research by replacing the first half-sentence with a reference to the stimulus (e.g., "This movie makes me think about myself" instead of "It was good to experience these feelings, because it makes me think about myself"). In addition, positive evaluations implied in the second half-sentence of some items might be cut to avoid a confounding influence on measures of positive evaluation (e.g., "I felt with the characters in the movie" instead of "because I like to feel with characters"). Moreover, the use of physiological measures and observational methods such as thought-listing, think aloud protocols, or recording of discussions among study participants would be useful to complement the introspective measures provided by the present research.

With these limitations in mind, the findings suggest that entertainment research could profit from expanding its current focus on rewarding aspects of moods and emotions per se to the interplay of emotion, cognition and interpersonal communication. A more in-depth understanding of audiences' social and cognitive needs may help elucidate the contribution of entertainment to more sustainable forms of psychological well-being beyond short-term affect regulation. Eventually, the indirect contribution of emotions to the satisfaction of psychosocial needs might help solve one of the most debated conundrums in entertainment research — that is, the question why entertainment audiences expose themselves voluntarily to painful or unpleasant feelings. The concept of eudaimonic well-being implies that individuals might be willing to accept painful feelings as a "necessary evil" to gain other, non-hedonistic forms of 
gratification. This concept does not explain however, why the "necessary evil" of exposure to unpleasant feelings should be necessary in the first place. The role of emotions in stimulating rewarding social and cognitive experiences may provide a possible answer here: If emotions, including unpleasant feelings, can promote the fulfillment of psychosocial needs (e.g., in that they stimulate experiences of insight, meaning, and interpersonal closeness among entertainment audiences), then they are not just an accidental byproduct of entertainment consumption but a causal factor that needs to be accepted to gain the desired gratification outcome. As already noted, however, additional research is needed to substantiate these kinds of causal explanations.

What can safely be concluded at this point is that social and cognitive gratifications are far more salient in individuals' introspective account of entertainment experience than they have been in entertainment research. For example, contemplative experiences and social sharing were rated among the most salient gratifications across gender, age groups, and educational levels (with somewhat higher levels of contemplativeness in older adults). This pattern of results seems to question the widespread notion of popular culture as an intellectually undemanding form of "low brow" entertainment, reminding us that deeper meaning is not within the work of art or entertainment but in the eyes of the beholder. Thus, entertainment research should assume that individuals' need for self-reflection, insight, and meaning is independent of sociodemographic factors, unless there is evidence to the contrary. 


\section{References}

Appel, M. (2008). Fictional narratives cultivate just-world beliefs. Journal of Communication, 58(1), 62-83. doi:10.1111/j.1460-2466.2007.00374.x

Aristotle. (trans. 1931). Nicomachean ethics (W. D. Ross, Trans.). London: Oxford University Press.

Bartsch, A., Appel, M., \& Storch, D. (2010). Predicting emotions and meta-emotions at the movies: The role of the need for affect in audiences' experience of horror and drama. Communication Research, 37(2), 167-190. doi:10.1177/0093650209356441

Bartsch, A. (in press). As time goes by. What changes and what remains the same in entertainment experience over the life span? Journal of Communication.

Bushman, B. J., \& Huesmann, L. R. (2000). Effects of televised violence on aggression. In D. G. Singer \& J. L. Singer (Eds.), Handbook of children and the media (pp. 223-254). Newbury Park, CA: Sage.

Busselle, R., \& Bilandzic, H. (2009). Measuring narrative engagement. Media Psychology, 12(4), 321-347. doi:10.1080/15213260903287259

Cohen, J. (2006). Audience identification with media characters. In J. Bryant \& P. Vorderer (Eds.), Psychology of entertainment (pp. 183-197). Mahwah, NJ: Lawrence Erlbaum.

Conway, J. C., \& Rubin, A. M. (1991). Psychological predictors of television viewing motivation. Communication Research, 18(4), 443-463. doi:10.1177/009365091018004001

Csikszentmihalyi, M. (1990). Flow: The psychology of optimal experience. New York, NY: Harper Collins.

Cupchik, G. C. (1995). Emotion in aesthetics: Reactive and reflective models. Poetics, 23(1-2), 177-188. doi:10.1016/0304-422X(94)00014-W

Cupchik, G. C. (2011). The role of feeling in the entertainment=emotion formula. Journal of Media Psychology, 23(1), 6-11. doi:10.1027/1864-1105/a000025 
Feshbach, S., \& Singer, R. D. (1971): Television and aggression: An experimental field study. San Francisco, CA: Jossey-Bass.

Giles, D. C. (2002). Parasocial interaction: A review of the literature and a model for future research. Media Psychology, 4(3), 279-305. doi:10.1207/S1532785XMEP0403_04

Green, M. C., \& Brock, T. C. (2000). The role of transportation in the persuasiveness of public narratives. Journal of Personality and Social Psychology, 79(5), 701-721. doi:10.1037/0022-3514.79.5.701

Hall, A. (2005). Audience personality and the selection of media and media genres. Media Psychology, 7(4), 377-398. doi:10.1207/S1532785XMEP0704_4

Hoffner, C. (1996). Children's wishful identification and parasocial interaction with favorite television characters. Journal of Broadcasting \& Electronic Media, 40(3), 389-402. doi:10.1080/08838159609364360

Hoffner, C., Fujioka, Y., Ibrahim, A., \& Ye, J. (2002). Emotion and coping with terror. In B. S. Greenberg (Ed.), Communication and terrorism (pp. 229-244). Cresskill, NJ: Hampton Press.

Hoffner, C. A., \& Levine, K. J. (2005). Enjoyment of mediated fright and violence: A metaanalysis. Media Psychology, 7(2), 207-237.doi:10.1207/S1532785XMEP0702_5

Ibrahim, A., Ye, J., \& Hoffner, C. (2008). Diffusion of news of the Shuttle Columbia Disaster: The role of emotional responses and motives for interpersonal communication. Communication Research Reports, 25(2), 91-101. doi:10.1080/08824090802021970

Katz, E., Haas, H., \& Gurevitch, M. (1973). On the use of the mass media for important things. American Sociological Review, 38(2), 164-181. doi:10.2307/2094393

Keyes, C. L. M., Shmotkin, D., \& Ryff, C. D. (2002). Optimizing well-being: The empirical encounter of two traditions. Journal of Personality and Social Psychology, 82(6), 1007-1022. doi:10.1037/0022-3514.82.6.1007

Klimmt, C., Hartmann, T., \& Schramm, H. (2006). Parasocial interactions and relationships. In 
J. Bryant \& P. Vorderer (Eds.), Psychology of entertainment (pp. 291-313). Mahwah, NJ: Lawrence Erlbaum Associates.

Klimmt, C., Hartmann, T., Schramm, H., \& Vorderer, P. (2003, May). The perception of avatars: Parasocial interactions with digital characters. Paper presented at the annual meeting of the International Communication Association, San Diego, CA.

Klimmt, C., Hefner, D., \& Vorderer, P. (2009). The video game experience as "true" identification: A theory of enjoyable alterations of players' self- perception. Communication Theory, 19(4), 351-373. doi:10.1111/j.1468-2885.2009.01347.x

Klimmt, C., Hefner, D., Vorderer, P., Roth, C., \& Blake, C. (2010). Identification with video game characters as automatic shift of self-perceptions. Media Psychology, 13(4), 323338. doi:10.1080/15213269.2010.524911

Knobloch-Westerwick, S. (2006). Mood management: Theory, evidence, and advancements. In J. Bryant \& P. Vorderer (Eds.), Psychology of entertainment (pp. 239-254). Mahwah, NJ: Lawrence Erlbaum Associates.

Lang, P. J. (1980). Behavioral treatment and bio-behavioral treatment: Computer applications. In J. B. Sidowski, J. H. Johnson, \& T. A. Williams (Eds.), Technology in mental health care delivery systems (pp. 119-137). Norwood, NJ: Ablex.

Larsen, J. T., McGraw, A. P., \& Cacioppo, J. T. (2001). Can people feel happy and sad at the same time? Journal of Personality and Social Psychology, 81(4), 684-696. doi:10.1037/0022-3514.81.4.684

Lull, J. (1990). Inside family viewing: Ethnographic research on television's audiences. London: Routledge.

Mares, M.-L., \& Cantor, J. (1992). Elderly viewers' responses to televised portrayals of old age. Communication Research, 19(4), 459-478. doi:10.1177/009365092019004004

Maslow, A. H. (1943). A theory of human motivation. Psychological Review, 50(4), 370-396. doi:10.1037/h0054346 
Miles, M. B., \& Huberman, A. M. (1994). Qualitative data analysis: An expanded sourcebook. Thousand Oaks, CA: Sage Publications.

Mills, J. (1993). The appeal of tragedy: An attitude interpretation. Basic and Applied Social Psychology, 14(3), 255-271.doi:10.1207/s15324834basp1403_1

Oliver, M. B. (1993). Exploring the paradox of the enjoyment of sad films. Human Communication Research, 19(3), 315-342. doi:10.1111/j.1468-2958.1993.tb00304.x

Oliver, M. B. (2008). Tender affective states as predictors of entertainment preference. Journal of Communication, 58(1), 40-61. doi:10.1111/j.1460-2466.2007.00373.x

Oliver, M. B., \& Bartsch, A. (2010). Appreciation as audience response: Exploring entertainment gratifications beyond hedonism. Human Communication Research, 36(1), 53-81. doi:10.1111/j.1468-2958.2009.01368.x

Oliver, M. B., \& Hartmann, T. (2010). Exploring the role of meaningful experiences in users' appreciation of good movies. Projections, 4(2), 128-150. doi:10.3167/proj.2010.040208

Oliver, M. B., Limparos, A., Tamul, D., \& Woolley, J. (2009, May). The role of mixed affect in the experience of meaningful entertainment. Paper presented at the annual meeting of the International Communication Association, Chicago, IL.

Oliver, M. B., \& Raney, A. A. (2011). Entertainment as pleasurable and meaningful: Identifying hedonic and eudaimonic motivations for entertainment consumption. Journal of Communication, 61(5), 984-1004. doi:10.1111/j.1460-2466.2011.01585.x

Patton, M. (2002). Qualitative research and evaluation methods. 3rd ed. Thousand Oaks, CA: Sage Publications.

Raney, A. A., \& Bryant, J. (2002). Moral judgment and crime drama: An integrated theory of enjoyment. Journal of Communication, 52(2), 402-415. doi:10.1111/j.14602466.2002.tb02552.x

Reinecke, L., Tamborini, R., Grizzard, M., Lewis, R., Eden, A., \& David Bowman, N. (in press). Characterizing mood management as need satisfaction: The effects of intrinsic 
needs on selective exposure and mood repair. Journal of Communication. doi:10.1111/j.1460-2466.2012.01649.x

Reinecke, L., \& Trepte, S. (2008). In a working mood?: The effects of mood management processes on subsequent cognitive performance. Journal of Media Psychology, 20(1), 3-14. doi:10.1027/1864-1105.20.1.3

Renaud, D., \& Unz, D. (2006). Die M-DAS - eine modifizierte Version der Differentiellen Affekt Skala zur Erfassung von Emotionen bei der Mediennutzung. Zeitschrift für Medienpsychologie, 18(2), 70-75. doi:10.1026/1617-6383.18.2.70

Rimé, B. (2007). The social sharing of emotion as an interface between individual and collective processes in the construction of emotional climates. Journal of Social Issues, 63(2), 307-322. doi:10.1111/j.1540-4560.2007.00510.x

Rubin, A. M. (1983). Television uses and gratifications: The interactions of viewing patterns and motivations. Journal of Broadcasting, 27(1), 37-51. doi:10.1080/08838158309386471

Rubin, A. M., \& Perse, E. M. (1987). Audience activity and soap opera involvement: A uses and effects investigation. Human Communication Research, 14(2), 246-268. doi:10.1111/j.1468-2958.1987.tb00129.x

Ryan, R. M., Huta, V., \& Deci, E. L. (2006). Living well: a self-determination theory perspective on eudaimonia. Journal of Happiness Studies, 9(1), 139-170. doi:10.1007/s10902-006-9023-4

Sherry, J. L. (2004). Flow and media enjoyment. Communication Theory, 14(4), 328-347. doi:10.1111/j.1468-2885.2004.tb00318.x

Tamborini, R., Bowman, N. D., Eden, A., Grizzard, M., \& Organ, A. (2010). Defining media enjoyment as the satisfaction of intrinsic needs. Journal of Communication, 60(4), 758777. doi:10.1111/j.1460-2466.2010.01513.x

Tesser, A., Millar, K., \& Wu, C. H. (1988). On the perceived functions of movies. Journal of 
Psychology, 122(5), 441-449.

Vorderer, P. (1993). Audience involvement and program loyalty. Poetics, 22(1-2), 89-98. doi:10.1016/0304-422X(93)90022-9

Vorderer, P., Klimmt, C., \& Ritterfeld, U. (2004). Enjoyment: At the heart of media entertainment. Communication Theory, 14(4), 388-408. doi:10.1111/j.14682885.2004.tb00321.x

Vorderer, P., \& Ritterfeld, U. (2009). Digital games. In R. L. Nabi \& M. B. Oliver (Eds.), Handbook of media processes and effects (pp. 455-467). Thousand Oaks, CA: Sage.

Vorderer, P., Steen, F., \& Chan, E. (2006). Motivation. In J. Bryant \& P. Vorderer (Eds.), Psychology of entertainment (pp. 3-17). Mahwah, NJ: Lawrence Erlbaum Associates.

Waterman, A. S. (1993). Two conceptions of happiness: Contrasts of personal expressiveness (eudaimonia) and hedonic enjoyment. Journal of Personality and Social Psychology, 64(4), 678-691. doi:10.1037/0022-3514.64.4.678

Watson, D., Clark, L. A., \& Tellegen, A. (1988). Development and validation of brief measures of positive and negative affect: The PANAS scales. Journal of Personality and Social Psychology, 54(6), 1063-1070. doi:10.1037/0022-3514.54.6.1063

Zillmann, D. (1988). Mood management through communication choices. American Behavioral Scientist, 31(3), 327-340. doi:10.1177/000276488031003005

Zillmann, D. (1996). The psychology of suspense in dramatic exposition. In P. Vorderer, H. J. Wulff \& M. Friedrichsen (Eds.), Suspense: Conceptualizations, theoretical analyses, and empirical explorations (pp. 199-231). Mahwah, NJ: Lawrence Erlbaum Associates.

Zillmann, D., \& Cantor, J. R. (1977). Affective responses to the emotions of a protagonist. Journal of Experimental Social Psychology, 13(2), 155-165. doi:10.1016/S00221031(77)80008-5

Zillmann, D., Weaver, J. B., Mundorf, N., \& Aust, C. F. (1986). Effects of an opposite-gender 
companion's affect to horror on distress, delight, and attraction. Journal of Personality and Social Psychology, 51(3), 586-594. doi:10.1037/0022-3514.51.3.586

Zuckerman, M. (1979). Sensation seeking: Beyond the optimal level of arousal. Hillsdale, NJ: Lawrence Erlbaum Associates. 
Figure 1

A preliminary two-level model of emotional gratification in entertainment experience.

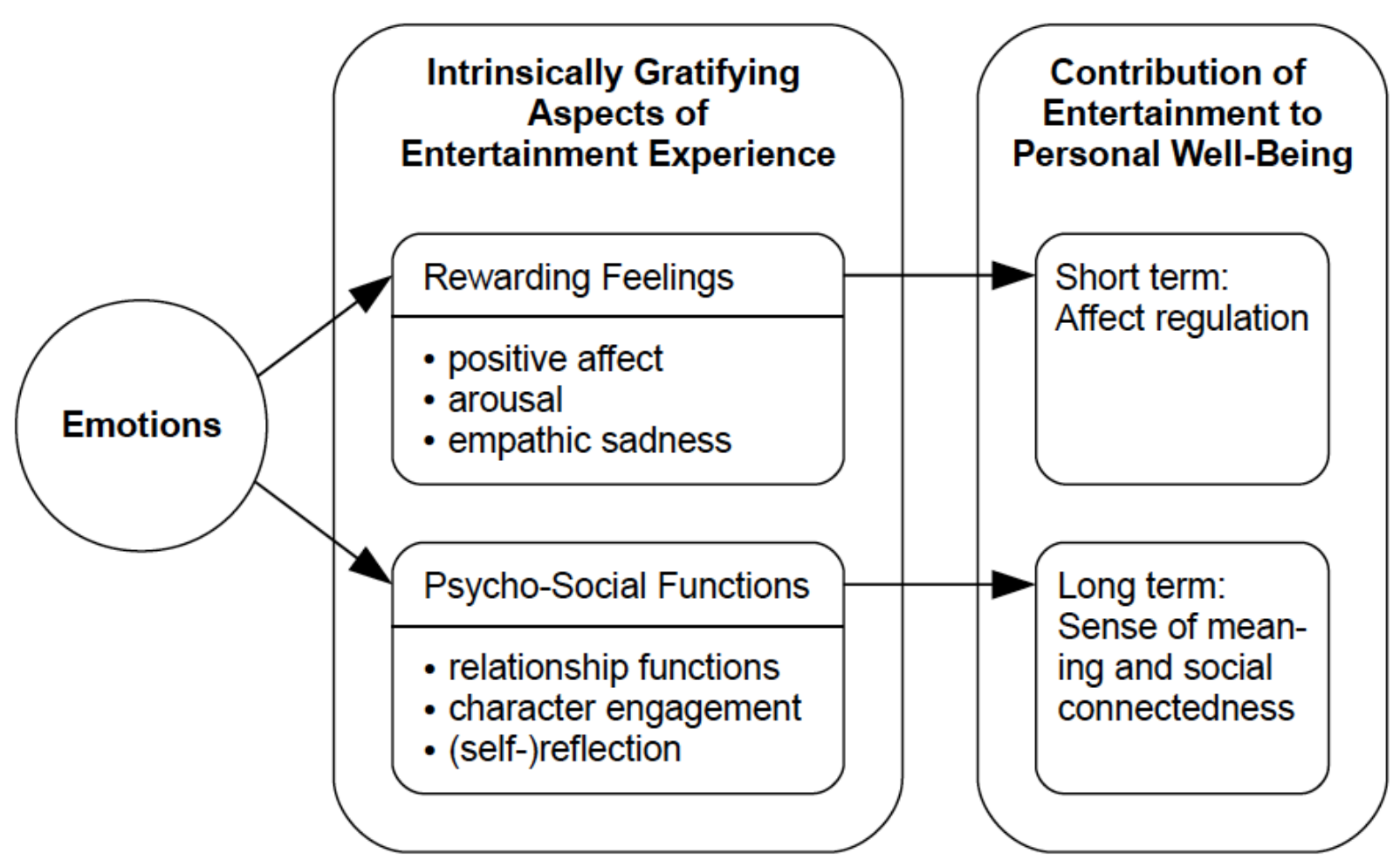


Table 1

Studies 2, 3, and 4: Factor Loadings for the Revised Emotional Gratification Scales (Study 4),

Eigenvalues, Variance Explained, Reliabilites, and Descriptive Statistics for Studies 2, 3 and 4.

\begin{tabular}{|c|c|c|c|c|c|c|c|c|}
\hline \multirow[b]{2}{*}{ It was good to experience these feelings... } & \multicolumn{7}{|c|}{ EFA } & \multirow[t]{2}{*}{ CFA } \\
\hline & $\mathrm{F} 1$ & $\mathrm{~F} 2$ & F3 & $\mathrm{F} 4$ & F5 & F6 & F7 & \\
\hline \multicolumn{9}{|l|}{ F1: Contemplative Experiences } \\
\hline $\begin{array}{l}\text {...because it encourages me to focus on things that are } \\
\text { important to me. }\end{array}$ & .72 & .12 & .20 & .19 & .15 & .12 & .06 & .72 \\
\hline $\begin{array}{l}\text {...because it inspires me to think about meaningful } \\
\text { issues. }\end{array}$ & .72 & .08 & .09 & .02 & .21 & .07 & .27 & .71 \\
\hline ...because it inspires new insights. & .72 & -.10 & .05 & .12 & .11 & .08 & .10 & .57 \\
\hline ...because it makes me think about myself. & .61 & .09 & .04 & .18 & .23 & .31 & .06 & .68 \\
\hline \multicolumn{9}{|l|}{ F2: Fun } \\
\hline ...because it makes me laugh. & -.03 & .82 & -.21 & .05 & -.04 & .06 & .12 & .90 \\
\hline ...because it puts me in a good mood. & .03 & .78 & .10 & .02 & .13 & -.02 & .03 & .61 \\
\hline ...because it amuses me. & -.05 & .77 & -.08 & -.02 & -.04 & -.08 & .11 & .70 \\
\hline ...because it is funny. & .21 & .56 & -.09 & .04 & -.12 & -.12 & -.08 & .55 \\
\hline \multicolumn{9}{|l|}{ F3: Thrill } \\
\hline ...because I like the adrenaline I get from it. & .07 & -.08 & .82 & .15 & .18 & .13 & .08 & .83 \\
\hline ...because I enjoy the thrill of it. & .14 & -.18 & .80 & .14 & .10 & .08 & .11 & .78 \\
\hline ...because I enjoy the excitement of it. & .06 & .05 & .74 & .16 & .13 & .26 & .20 & .76 \\
\hline ...because I like the tension associated with it. & .07 & -.10 & .71 & .16 & .18 & .24 & .07 & .74 \\
\hline \multicolumn{9}{|l|}{ F4: Character Engagement } \\
\hline ...because I like to feel with characters. & .10 & .03 & .19 & .80 & .12 & .26 & .12 & .87 \\
\hline ...because I like to slip into the role of characters. & .07 & -.06 & .23 & .78 & .19 & .06 & .12 & .79 \\
\hline $\begin{array}{l}\text {...because I identify with the characters' outlook on } \\
\text { life. }\end{array}$ & .24 & .06 & -.02 & .71 & .12 & .01 & .07 & .80 \\
\hline $\begin{array}{l}\text {...because I like to live through and share the } \\
\text { characters' experiences. }\end{array}$ & .11 & .08 & .34 & .68 & .14 & .22 & .08 & .79 \\
\hline \multicolumn{9}{|l|}{ F5: Vicarious Release of Emotions } \\
\hline $\begin{array}{l}\text {...because it allows me to experience feelings that I } \\
\text { cannot act on in everyday life. }\end{array}$ & .15 & -.07 & .23 & .14 & .83 & .12 & .01 & .87 \\
\hline $\begin{array}{l}\text {...because it allows me to experience emotions that I } \\
\text { avoid in everyday life. }\end{array}$ & .16 & -.07 & .19 & .13 & .82 & .15 & .04 & .86 \\
\hline $\begin{array}{l}\text {...because I can experience feelings that are difficult } \\
\text { for me to allow in everyday life. }\end{array}$ & .16 & -.01 & .18 & .15 & .81 & .17 & -.02 & .81 \\
\hline $\begin{array}{l}\text {...because it allows me to experience feelings that I } \\
\text { normally have to hide in everyday life.* }\end{array}$ & .41 & .10 & -.01 & .19 & .61 & .13 & .01 & .62 \\
\hline
\end{tabular}

F6: Empathic Sadness 


\begin{tabular}{|c|c|c|c|c|c|c|c|c|c|}
\hline \multirow{2}{*}{\multicolumn{2}{|c|}{ It was good to experience these feelings... }} & \multicolumn{7}{|c|}{ EFA } & \multirow[t]{2}{*}{ CFA } \\
\hline & & F1 & $\mathrm{F} 2$ & $\mathrm{~F} 3$ & $\mathrm{~F} 4$ & F5 & F6 & F7 & \\
\hline \multicolumn{2}{|c|}{...because I like being moved to tears. } & .08 & -.06 & .18 & .17 & .16 & .86 & .05 & .90 \\
\hline \multicolumn{2}{|c|}{...because I like to have a good cry. } & .11 & -.05 & .03 & .03 & .15 & .85 & .06 & .76 \\
\hline \multicolumn{2}{|c|}{...because I like moments of sadness and poignancy.* } & .15 & -.11 & .27 & .15 & .05 & .78 & .05 & .80 \\
\hline \multicolumn{2}{|c|}{...because I like to be overwhelmed with emotion.* } & .15 & .00 & .24 & .13 & .14 & .78 & .05 & .83 \\
\hline \multicolumn{10}{|c|}{ F7: Social Sharing of Emotions } \\
\hline \multicolumn{2}{|c|}{$\begin{array}{l}\text {...because it inspires me to talk about the movie (TV } \\
\text { series) with others. }\end{array}$} & .02 & .06 & .09 & .11 & -.06 & .05 & .84 & .79 \\
\hline \multicolumn{2}{|c|}{$\begin{array}{l}\text {...because it stimulates the exchange of comments } \\
\text { while watching the movie (TV series). }\end{array}$} & .14 & .06 & .02 & .13 & -.08 & .03 & .83 & .81 \\
\hline \multicolumn{2}{|c|}{$\begin{array}{l}\text {...because it encourages me to discuss issues with } \\
\text { others. }\end{array}$} & .23 & -.07 & .06 & .04 & .12 & .11 & .81 & .76 \\
\hline \multicolumn{2}{|c|}{$\begin{array}{l}\text {...because it makes me curious to find out how others } \\
\text { experienced the movie (TV series). }\end{array}$} & .04 & .11 & .23 & .04 & .07 & .01 & .65 & .55 \\
\hline \multirow{2}{*}{$\begin{array}{l}\text { Studies } 2 / 3 \\
\text { combined: }\end{array}$} & Eigenvalues & 23.35 & 6.40 & 3.81 & 2.97 & 2.15 & 1.85 & 1.7 & \\
\hline & $\%$ Variance Explained & 27.80 & 8.81 & 4.54 & 3.54 & 2.56 & 2.20 & 1.99 & \\
\hline \multicolumn{2}{|c|}{ Study 2:Eigenvalues } & 23.97 & 7.17 & 2.71 & 2.97 & 4.62 & 2.71 & 1.76 & \\
\hline & $\%$ Variance Explained & 28.53 & 9.18 & 2.50 & 3.54 & 5.50 & 3.24 & 1.99 & \\
\hline & Cronbach's $\alpha$ & .85 & .88 & .78 & .81 & .82 & .76 & .71 & \\
\hline & $M$ & 2.90 & 3.47 & 2.67 & 3.08 & 2.37 & 2.12 & 3.17 & \\
\hline & $S D$ & 1.13 & 1.24 & 1.06 & 1.05 & 1.04 & 1.08 & 1.01 & \\
\hline \multicolumn{2}{|c|}{ Study 3:Eigenvalues } & 23.33 & 7.42 & 3.05 & 3.80 & $* *$ & 2.16 & 1.99 & \\
\hline & $\%$ Variance Explained & 27.78 & 8.84 & 3.63 & 4.53 & $* *$ & 2.57 & 2.73 & \\
\hline & Cronbach's $\alpha$ & .84 & .84 & .81 & .80 & .73 & .74 & .80 & \\
\hline & $M$ & 2.91 & 3.03 & 2.69 & 2.97 & 2.03 & 2.38 & 3.10 & \\
\hline & $S D$ & 1.16 & 1.18 & 1.11 & 1.06 & 0.97 & 1.25 & 1.01 & \\
\hline \multicolumn{2}{|c|}{ Study 4:Eigenvalues } & 1.41 & 1.11 & 2.93 & 1.72 & 2.34 & 7.81 & 1.86 & \\
\hline & $\%$ Variance Explained & 5.05 & 3.79 & 10.45 & 6.15 & 8.35 & 27.89 & 6.65 & \\
\hline & Cronbach's $\alpha$ & .76 & .76 & .86 & .82 & .88 & .89 & .81 & \\
\hline & $M$ & 3.01 & 4.35 & 3.51 & 3.63 & 2.57 & 2.81 & 3.46 & \\
\hline & $S D$ & 0.84 & 0.64 & 1.01 & 0.93 & 1.04 & 1.09 & 0.91 & \\
\hline
\end{tabular}

Notes: *Items with asterisks were added in Study 4 to complement scales with less than four items. **Eigenvalue and variance explained are not reported for the factor vicarious release of emotions in Study 3 because it did not emerge as an independent factor in this study. 
Table 2

Studies 2 and 3: Hierarchical Regression Analysis of Emotions and Meta-Emotions as

Predictors of Emotional Gratification Ratings, Controlling for Rating Task, Film Genre, Age, Gender, and Education.

\begin{tabular}{|c|c|c|c|c|c|c|c|}
\hline & Fun & Thrill & $\begin{array}{l}\text { Empathic } \\
\text { Sadness }\end{array}$ & $\begin{array}{l}\text { Contem- } \\
\text { plative }\end{array}$ & $\begin{array}{l}\text { Character } \\
\text { Engagement }\end{array}$ & $\begin{array}{l}\text { Social } \\
\text { Sharing }\end{array}$ & $\begin{array}{l}\text { Vicarious } \\
\text { Release }\end{array}$ \\
\hline \multicolumn{8}{|l|}{ Step 1} \\
\hline Rating Task & $-.17 * * *$ & .00 & $.11^{*}$ & .02 & -.05 & -.06 & $-.16 * * *$ \\
\hline $\mathrm{R}^{2}$ & .03 & .00 & .01 & .00 & .00 & .00 & .02 \\
\hline$F$ & $13.10 * * *$ & 0.01 & $5.73^{*}$ & 0.27 & 1.17 & 1.51 & $12.08 * *$ \\
\hline \multicolumn{8}{|l|}{ Step 2} \\
\hline Light & $.39 * * *$ & -.02 & .00 & -.03 & .10 & .06 & .00 \\
\hline Serious & $-.31 * * *$ & -.08 & $.12 *$ & $.20 * * *$ & .06 & -.05 & .05 \\
\hline Action & -.06 & $.23 * * *$ & -.05 & $-.15 * *$ & -.02 & $-.11 *$ & .06 \\
\hline $\mathrm{R}^{2}$ Change & .33 & .07 & .02 & .08 & .01 & .02 & .00 \\
\hline$F$ Change & $78.41 * * *$ & $11.74 * * *$ & $3.16^{*}$ & $13.53 * * *$ & 2.17 & 2.97 & 0.62 \\
\hline \multicolumn{8}{|l|}{ Step 3} \\
\hline Gender (male) & .04 & .08 & $-.11 *$ & -.05 & -.09 & $-.13 * *$ & .03 \\
\hline Age 18-25 & -.04 & -.04 & -.05 & -.10 & .07 & .01 & -.03 \\
\hline Age $50+$ & $-.12 *$ & $-.18 * * *$ & $-.13 *$ & $.11^{*}$ & .01 & .11 & -.06 \\
\hline Education & .02 & .00 & .00 & .05 & .01 & .08 & $-.14 * *$ \\
\hline $\mathrm{R}^{2}$ Change & .01 & .03 & .02 & .03 & .01 & .03 & .02 \\
\hline$F$ Change & $2.17 *$ & $3.59 * *$ & $2.60 *$ & $3.58 * *$ & 1.64 & $3.16^{*}$ & $2.25^{*}$ \\
\hline
\end{tabular}

Step 4

\begin{tabular}{|c|c|c|c|c|c|c|c|}
\hline SAM Arousal & -.04 & $.24 * * *$ & $.10^{*}$ & $.15^{* *}$ & $.15^{* *}$ & $.13^{* *}$ & $.12 * *$ \\
\hline SAM Valence & $.29 * * *$ & -.01 & -.08 & $-.28 * * *$ & -.03 & -.09 & -.11 \\
\hline Meta-Emotion & $.36 * * *$ & $.36^{* * *}$ & $.24 * * *$ & $.25 * * *$ & $.40 * * *$ & $.19 * * *$ & $.14^{*}$ \\
\hline $\mathrm{R}^{2}$ Change & .24 & .16 & .05 & .08 & .14 & .04 & .03 \\
\hline$F$ Change & $95.73 * * *$ & $31.81 * * *$ & $7.78 * * *$ & $15.24 * * *$ & $26.56 * * *$ & $6.64 * * *$ & $4.69 * *$ \\
\hline
\end{tabular}

Note: Scores are standardized regression weights at entry into the model. 


\section{Table 3}

Studies 2 and 3: Hierarchical Regression Analysis of Emotional Gratification Ratings as

Predictors of Different Aspects of Movie Evaluation, Controlling for Rating Task, Film Genre, Age, Gender, and Education.

Lasting

Good Movie Entertaining Artistic Value Impression

\begin{tabular}{|c|c|c|c|c|}
\hline \multicolumn{5}{|l|}{ Fun } \\
\hline Beta & $.28 * * *$ & $.48^{* * *}$ & .10 & .08 \\
\hline $\mathrm{R}^{2}$ Change & .05 & .15 & .01 & .00 \\
\hline$F$ Change & $31.69 * * *$ & $99.72 * * *$ & 3.61 & 2.18 \\
\hline \multicolumn{5}{|l|}{ Thrill } \\
\hline Beta & $.18 * * *$ & $.15^{* * *}$ & .07 & $.17 * * *$ \\
\hline $\mathrm{R}^{2}$ Change & .03 & .02 & .00 & .03 \\
\hline$F$ Change & $17.37 * * *$ & $12.33 * * *$ & 2.99 & $14.98 * * *$ \\
\hline \multicolumn{5}{|c|}{ Empathic Sadness } \\
\hline Beta & $.12 * *$ & .04 & .05 & .04 \\
\hline $\mathrm{R}^{2}$ Change & .01 & .00 & .00 & .00 \\
\hline$F$ Change & $7.53 * *$ & .80 & 1.19 & 1.04 \\
\hline \multicolumn{5}{|l|}{ Contemplative } \\
\hline Beta & $.29 * * *$ & .04 & $.27 * * *$ & $.27 * * *$ \\
\hline $\mathrm{R}^{2}$ Change & .07 & .00 & .06 & .06 \\
\hline$F$ Change & $45.90 * * *$ & .84 & $39.73 * * *$ & $39.67 * * *$ \\
\hline \multicolumn{5}{|c|}{ Character Engagement } \\
\hline Beta & $.27 * * *$ & $.21 * * *$ & $.25^{* * *}$ & $.23 * * *$ \\
\hline $\mathrm{R}^{2}$ Change & .07 & .04 & .06 & .05 \\
\hline$F$ Change & $42.24 * * *$ & $25.92 * * *$ & $38.81 * * *$ & $31.98 * * *$ \\
\hline \multicolumn{5}{|l|}{ Social Sharing } \\
\hline Beta & $.14 * *$ & .04 & $.15^{* * *}$ & $.14 * * *$ \\
\hline $\mathrm{R}^{2}$ Change & .02 & .00 & .02 & .02 \\
\hline$F$ Change & $10.70 * *$ & .74 & $12.80 * * *$ & $11.64 * *$ \\
\hline \multicolumn{5}{|c|}{ Vicarious Release } \\
\hline Beta & $10 *$ & .05 & .04 & $11 * *$ \\
\hline $\mathrm{R}^{2}$ Change & .01 & .00 & .00 & .01 \\
\hline$F$ Change & $5.97 *$ & 1.59 & 0.92 & $6.69 * *$ \\
\hline
\end{tabular}

${ }^{*} p<.05 .^{* *} p<.01{ }^{* * *} p<.001$.

Note: Scores are standardized regression weights at entry into the model. Each emotional gratification scale was entered in the last step of a separate regression equation to predict the movie evaluation variables, controlling for rating task, film genre, age, gender, and education. 
Table 4

Studies 2 and 3: Correlations of Emotional Gratification Ratings with Emotions Experienced

During the Movie

Empathic Contem- Character Social Vicarious

Fun Thrill Sadness plative Engagement Sharing Release

\section{PANAS}

\begin{tabular}{|c|c|c|c|c|c|c|c|}
\hline Positive Affect & $.25 * * *$ & $.25 * * *$ & $.26 * * *$ & $.27 * * *$ & $.39 * * *$ & $.26 * * *$ & .10 \\
\hline Negative Affect & $-.57 * * *$ & .05 & $.13^{*}$ & $.36 * * *$ & -.04 & -.02 & $.14^{*}$ \\
\hline \multicolumn{8}{|l|}{ MDAS } \\
\hline Joy & $.66^{* * *}$ & $.13 *$ & .06 & -.07 & $.19 * *$ & .00 & .04 \\
\hline Amusement & $.75 * * *$ & $.13^{*}$ & .02 & -.10 & $.20 * *$ & .00 & .01 \\
\hline Interest & .05 & $.24 * * *$ & .05 & $.30 * * *$ & $.33 * * *$ & $.30 * * *$ & .09 \\
\hline Surprise & .02 & $.19 * *$ & .04 & $.18 * *$ & $.23 * * *$ & $.26 * * *$ & .10 \\
\hline Fascination & -.01 & $.22 * * *$ & .07 & $.30 * * *$ & $.30 * * *$ & $.32 * * *$ & $.12 *$ \\
\hline Poignancy & $-.15 * *$ & $.13^{*}$ & $.17 * *$ & $.46^{* * *}$ & $.31 * * *$ & $.31 * * *$ & $.17 * *$ \\
\hline Sadness & $-.44 * * *$ & $-.12 *$ & $.13^{*}$ & $.39 * * *$ & $.15^{* *}$ & $.19 * *$ & $.12 *$ \\
\hline Anger & $-.47 * * *$ & -.10 & .03 & $.25 * * *$ & .03 & $.22 * * *$ & .08 \\
\hline Fear & $-.41 * * *$ & .07 & .08 & $.23 * * *$ & .10 & $.22 * * *$ & $.13^{*}$ \\
\hline Disgust & $-.41 * * *$ & -.04 & .00 & $.15^{*}$ & -.01 & .08 & $.14^{*}$ \\
\hline
\end{tabular}

$* \mathrm{p}<.05 . * * \mathrm{p}<.01 . * * * \mathrm{p}<.001$.

Note: Scores are Pearson correlations. 


\section{Table 5}

Study 4: Hierarchical Regression Analysis of TV Series, Individual Differences, and Emotions as Predictors of Emotional Gratification Ratings

Empathic Contem- Character Social Vicarious Fun Thrill Sadness plative Engagement Sharing Release

\section{Step 1}

$\begin{array}{llllllll}\text { Prison Break } & -.29 * * * & .27 * * * & .17 * * & .04 & .07 & .07 & .08\end{array}$

The Simpsons \begin{tabular}{llllllll}
$.24 * * *$ & $-.40 * * *$ & $-.33 * * *$ & -.07 & $-.21 * * *$ & .02 & $-.24 * * *$ \\
\cline { 2 - 7 }
\end{tabular}

$\mathrm{R}^{2}$

$.19 \quad .31$

$.31 \quad .17 \quad .01$

.06

.00
.08

F

$44.44 * * * \quad 82.24 * * * 38.77 * * * 1.53$

$12.36^{* * *}$

0.77

$16.14 * * *$

Step 2

\begin{tabular}{llllllll} 
Age & .02 & -.08 & -.07 & $.13 *$ & -.05 & -.09 & $-.13 *$ \\
Gender (male) & .02 & -.06 & $-.34 * * *$ & -.06 & -.08 & .03 & -.09 \\
Education & .00 & -.06 & -.02 & .01 & -.09 & -.03 & $-.14 * *$ \\
\cline { 2 - 7 } $\mathrm{R}^{2}$ Change & .00 & .01 & .09 & .02 & .01 & .01 & .03 \\
$F$ Change & 0.09 & 2.04 & $15.54 * * *$ & 2.31 & 1.71 & 1.16 & $4.74 * *$
\end{tabular}

Step 3

\begin{tabular}{|c|c|c|c|c|c|c|c|}
\hline Arousal & -.10 & $.39 * * *$ & $.15^{* *}$ & $.15^{*}$ & $.24 * * *$ & $.24 * * *$ & $.23 * * *$ \\
\hline Valence & $.28 * * *$ & .00 & -.06 & .00 & .01 & .06 & -.02 \\
\hline Meta-Emotion & $.26 * * *$ & $.15^{* * *}$ & $.12 * *$ & $.16^{* *}$ & $.21 * * *$ & .07 & $.10^{*}$ \\
\hline $\mathrm{R}^{2}$ Change & .17 & .14 & .04 & .04 & .09 & .05 & .05 \\
\hline$F$ Change & $33.07 * * *$ & $30.53 * * *$ & $6.15^{* * *}$ & $5.64 * *$ & $13.42 * * *$ & $6.68 * * *$ & $7.11 * * *$ \\
\hline
\end{tabular}

Note: Scores are standardized regression weights at entry into the model. 
Appendix A

German Scale Items

Ich fand es gut, diese Gefühle zu erleben, weil...

Fun $\quad 5$...weil es mich zum Lachen bringt.

6 ...weil es mich in eine gute Stimmung versetzt.

7 ...weil ich mich dabei gut amüsiere.

8 ...weil es lustig ist.

Thrill 9 ...weil ich den Adrenalin-Kick mag.

10 ...weil ich Spaß am Nervenkitzel habe.

11 ...weil ich die Aufregung genieße, die damit verbunden ist.

12 ...weil ich die Anspannung mag, die damit verbunden ist.

Empathic 21 ...weil ich es mag, wenn ich zu Tränen gerührt bin.

Sadness

22 ...weil ich es genieße, wenn ich weinen kann.

23 ...weil ich traurige und herzergreifende Momente mag.

24 ...weil ich es mag, wenn ich von Rührung überwältigt werde.

Contempla- 1 ...weil dadurch bestärkt werde, mich für Dinge einzusetzen, die mir wichtig sind. tive

Experiences 2 ...weil ich dadurch angeregt werde, mich mit wichtigen Themen auseinanderzusetzen.

3 ...weil ich dadurch neue Einsichten gewinne.

4 ...weil ich dadurch angeregt werde, über mich selbst nachzudenken.

Character 13 ...weil ich mich gerne in die Filmfiguren einfühle.

Engage-

ment

14 ...weil ich gerne in die Rolle der Filmfiguren schlüpfe.

15 ...weil mich mit dem Lebensgefühl der Filmfiguren identifiziere.

16 ...weil ich es mag, gemeinsam mit den Filmfiguren Dinge zu durchleben.

Social 25 ...weil ich dadurch angeregt werde, mich mit Anderen über den Film zu unterhalten.

Sharing of

Emotions

26 ...weil ich dadurch angeregt werde, mit Anderen Kommentare auszutauschen.

27 ...weil ich dadurch angeregt werde, mit Anderen über bestimmte Themen zu diskutieren.

28 ...weil es mich reizt, herauszufinden, wie Andere den Film erlebt haben.

Vicarious

17 ...weil es mir ermöglicht, Gefühle auszuleben, die ich im Alltag nicht ausleben kann.

Release of

Emotions

18 ...weil ich dadurch Gefühle erleben kann, die ich im Alltag vermeide.

19 ...weil ich dabei Gefühle erlebe, die ich im Alltag nicht zulassen kann.

20 ...weil ich dadurch Gefühle ausleben kann, die ich im Alltag verbergen muss. 